\title{
Teaching of Pragmatics: Issues in a Global Age*
}

\author{
Liwei Zhu \\ Tianjin Polytechnic University, China
}

\begin{abstract}
This article reviews literature on pragmatic teaching in three domains: (1) instructional methods in interpragmatics (2) pragmatic teaching resources (3) test and assessment of pragmatic ability .It aims at providing a comprehensive perspective of the available choices for pragmatics teaching and the ways that second language learners' pragmatic development can be enhanced in the classroom. In the area of instructional methods, this article reviews researches under the theoretical SLA framework of explicit versus implicit instruction, input processing instruction, and skill acquisition and practice. In the domain of pragmatic teaching resources, two types of pedagogical resources are reviewed: textbooks development and the possibility of the application of CA based research material and electronic corpora to the classroom pragmatics teaching and learning. In the discussion of test and assessment of pragmatic ability, two categories are reviewed. The first is the comparative study of the six types of instruments to test second language learners' pragmatic ability which is aimed to provide statistical and practical aspects for the test developers and test users. The second reviews the teacher assessment and its related assessment instruments in the application of pragmatic teaching .Finally, this article discusses unique challenges and opportunities pragmatics teaching faces in the current era.
\end{abstract}

Index Terms — pragmatic teaching, interpragmatics, pragmatic development

\section{INTRODUCTION}

The cultivation of pragmatic ability in second language teaching context has come into vogue in recent decades. Teaching of pragmatics to second language learners is a complicated issue involving different factors both inside and outside the classroom. Many researchers up till recently have done a lot of empirical studies which give insights as to the pragmatic teaching.

\section{A. Definition of Pragmatics}

What is the pragmatic ability that has gained such attention in second language pedagogy? Pragmatics has various definitions according to different standards and theoretical orientations. According to Crystal (1997, p301), pragmatics is "the study of language from the point of view of speakers, especially of the choices they make, the constraints they encounter in using language in social interaction and the effects their use of language has on other participants in the act of communication". Here, the act of communication involves not only speech acts such as apologizing and complaining but also different types of discourse. Pragmatics according to Kasper(2001, p2) should be seen as "interpersonal rhetoric" - the way speakers accomplish goals as social actors needing to get things done and attend to their interpersonal relationships with other people." Alco'n and Martı'nez-Flor (2008) tries to explain pragmatics from second language acquisition. It focuses on the investigation of speech acts, conversational structure and conversational implication. According to them, the study of second language pragmatics is referred to as interlanguage pragmatics (ILP), which distinguishes linguistic knowledge from social knowledge. Leech (1983) and Thomas (1983) divide pragmatics into two parts: pragmalinguistics and sociopragmatics. Pragmalinguistics refers to the linguistic resources for conveying communicative acts and interpersonal meanings; sociopragmatics refers to the social perceptions underlying participants' interpretation and performance of communicative acts.

\section{B. Pragmatic Teaching Overview}

The field of pragmatic teaching today deals with a range of issues faced by language learners and second language teachers who teach and assess them. Many of the issues addressed include the teaching approaches, the materials adopted in the classroom and the test and assessment. This article reviews a selection of the existing literature and discusses diverse issues related to pragmatics teaching and learning in three categories: (1) effectiveness of specific instructional methods of pragmatics learning; (2) instructional materials and resources for pragmatic development in formal classroom settings; (3) test and assessment utilized to evaluate learners' pragmatic ability.

\section{INSTRUCTIONAL METHODS IN INTERPRAGMATICS}

The examination of the instruction effect of pragmatic ability is based on the assumption that pragmatic competence is teachable in the second language classroom. The instructional methods discussed in the paper fall into two categories

\footnotetext{
* This paper is supported by a grant from Tianjin Philosophical and Social Sciences Planning Research Project in 2018 ---A Study Into the Use of Classroom Pragmatics Strategies by Preschool Teachers on Their Pupils (project number:TJWW18-012).
} 
in terms of theoretical basis. The first one is Schmidt's noticing hypothesis which claims that learners must notice second language features in input for subsequent development to occur in the acquisition of these features: Previous instructional studies have applied this theoretical paradigm by adopting various instructional methods such as explicit pragmatic information provision, input enhancement and consciousness raising of pragmalinguistic forms.

House (2008) studied the using of translation to improve pragmatic competence. He saw translation not only as a linguistic procedure (didactic function), but also an act of inter-cultural communication (pragmatic function). The conceptions in functional grammar are utilized when explaining his points. The context of situation is divided into three component: the ideational, the interpersonal and the textual which are equivalent to the semantic, the pragmatic and the textual aspect. He claims that if translation is used in a way that students can realize their pragmatic potential, it can be used as an exercise to relate linguistic forms to their communicative function. Translation would play an important role in developing learner's communicative competence. When designing the instructional methods, he mentioned the possibility of including translation activities such as the explicit comparison of cultural phenomena in the first and second language communities; the creative production of both source and target language texts; the changing of the Field, Tenor and Mode in the original text, the translated text or both and the evaluation of the translations from both teachers and language learners. He also made comparison between overt translation and covert translation and claimed that covert translation should be preferred over overt translation. In his study, translation is no longer seen as a tool to improve linguistic knowledge but as a way to promote learner's pragmatic competence and ability to recognize the contrasts between native and foreign cultures.

Another group of studies focusing on the awareness raising can serve as representative of the pragmatic teaching methods.

Kondo (2008) in her study provided some evidence that pragmatics could be taught through instruction; learners became aware of the pragmatic similarities and differences between their native language and the target language. In her opinion, second language learner is not the "model" native speaker. In the process of learning another language, he or she is creating a new interlanguage and identity. The successful communication is a "matter of optimal" instead of "total convergence". The language learner should reflect on their linguistic choices, compare linguistic features and come up with an interlanguage of their own. The study explored how learner's choices of refusal strategies changed after explicit instruction involving fives steps (feeling, doing, thinking, understanding and using). The comparisons between JEB (Japanese Learners of English before instruction) and JEA (Japanese learners of English after instruction) showed that after instruction their choice of refusal strategies changed and became more similar to the American pattern. However, they still retained some culturally specific features of their own language. However, there are some limitations as to this study. First, when the data was acquired in pre-test and post-test, the instrument used was Oral Discourse Completion Task (ODCT), which required students to read a written description of a situation and to say aloud what they would say in that situation into a tape recorder. This probably would only reflect student's metapragmatic knowledge instead of their real interpragmatic ability, since speakers' intuition about their language use might be different from what they actually say. The real time interaction requires people's immediate response which allows no second thinking or pause. The second language learners could still forget the appropriate answer. Another limitation as the author said herself is the relatively small number of subjects involved in the instruction and the lack of a control group. However, it still has shed some light on the kinds of pragmatic knowledge learners can acquire through instructions.

The effectiveness of awareness raising instruction method was further confirmed by a study by Liddicoat and Crozet (2001). The starting point for this research was the teaching of the question "T'as passé un bon week-end?"(Did you have a good weekend?), because it presents cross-cultural difficulties between speakers of French and speakers of Australian English. The participants of the study are a group of French learners. However, in the French cultural context, the question is not a ritualized one. It is used to start a conversation and the resulting talk is quite long. The teaching activities were divided into four phases according to the methodology developed in Crozet (1996): awareness-raising phase, experimentation phase, production phase and feedback phase. After one year's instruction, the students had developed an awareness of culture norms in the target-language group. This study has shown that interaction norms can be acquired even within a short-term program. However, it seemed that not all elements of discourse were equally learned. The elements which related to the content of talk are more easily learned and integrated into target language interaction than those related to the language form. The study seems to suggest that cultural variability is easier to instruct because the impact of noticing can be more readily integrated into talk. This study brought new insights into pragmatics by incorporating some key concepts: conversational style, conversation content and awareness raising. Although the study focuses on a single speech event, the real issue deserves our attention is that identical utterances in two different languages may actually have very different pragmatic and cultural meanings.

Another theoretical paradigm as guiding framework for pragmatics instruction is input processing and skill acquisition theories. The input processing theory aims to describe cognitive process that is involved when the learner is processing input (VanPatten, 1996, 2007). Input processing theory have recently been applied to pragmatics instruction in a study by Takimoto (2009), which studied the effects of input processing instruction on learning request forms in L2 English. He applied three types of tasks: (1) input with explicit metapragmatic information; (2) input without explicit information; (3) problem-solving tasks. Learners first listened to a conversation with request forms and evaluated their appropriateness. Four types of tasks were used to assess the instructional effect: a discourse completion task, a role-play 
task, a written appropriateness judgment task, and a listening appropriateness judgment task. The three experimental groups outperformed the control group, but there were no significant differences among the treatment groups in the posttest. A delayed posttest revealed the sustained effect of structured input tasks. His research has proved the effectiveness of processing instruction.

Input processing theory and instruction have also been used in the instruction of Chinese pragmatics. Li (2012) examined the effects of explicit metapragmatic information and structured input tasks on learning request forms in Chinese. Building on the cognitive theory of the ACTR model (Anderson, 1993), he regards acquisition of pragmatic rules as a transition from declarative knowledge to procedural knowledge. The ultimate goal of skill acquisition is to reach a stage when one's language ability becomes automatic, leading to fluent, accurate performance.

$\mathrm{Li}$ investigated whether different amounts of practice could produce different effects in the speech act of requests. Learners were divided into three groups: an intensive training group, a regular training group, and a control group. The intensive and regular training groups received explicit instruction on request forms. The intensive group practiced twice as much as the regular group. The control group received metapragmatic explanation but had no practice. Two methods were used to assess the learning results: a listening appropriateness judgment task and an oral discourse completion task. Results didn't show difference on accurate judgment of request forms in the listening task. As to response times, the intensive group's speed became significantly faster after practice, however the other two groups didn't show such effects. Analysis of the oral production of requests also showed complicated results. The effect of practice wasn't as significant on fluency as it was on accuracy. To a certain degree, the research results have proved skill acquisition theory which claims that declarative knowledge is shared among different skills (e.g., listening and speaking), but procedural knowledge requires skill-specific practice (DeKeyser, 2007).

\section{Pragmatic Teaching Resources}

Teaching pragmatics involve the use of linguistic resources for both performing communicative acts and explaining social perceptions of these acts. So teaching materials should include several key elements: social context, functional language use, and interaction. Therefore, teaching materials and resources should be designed in a way to incorporate these important elements.

Ishihara (2010) in her study briefly reviewed the researches on pragmatic teaching resources in recent years. According to the study, when teaching pragmatics to second language learners, teachers should adapt their teaching materials or prepare supplement teaching resources. According to the previous research, among the present pragmatic instruction materials, very few of them are based on the empirical studies. Most of the publications on EFL teaching are based on the native speaker's intuition; the conversations in the text tend to be rigid and sometimes pragmatic factors are not taken into consideration or treated as one of the teaching objectives. The American English was taken as an example; the act of closing a conversation is very complex and involves a lot of take turning( the shutdown, the pre-closing, the terminal exchange). The researcher found that the conversations in many textbooks (eight out of twenty) didn't have complete closing. The study mentioned an investigation about the speech act of complaint in seven English textbooks which found that there was a mismatch between what was written in the textbook and the spontaneous conversation. According to the study, complaints in real conversation often function as a bonding device or creating solidarity between conversation partners. However, this function was misrepresented in most of the textbooks as an expression of negative feeling or dissatisfaction. The author also found that EFL textbooks contained little explicit information about pragmatics for the teachers to explicate. The range of the speech acts included in the textbook was very limited and there wasn't enough sampling of the conversation for the students to detect the conversational implicature. One study she mentioned focused on the speech act of request in an EFL tourism textbook published in Spain. It found that there was a lack the contextual information for these requests and it tended to neglect the use of modifiers. Another study compared the greetings in seven EFL textbooks in Japan and naturally occurring greetings in American English and found that textbooks misrepresented naturally occurring greetings. She also found that in many of the Japanese language textbooks, there was a clear boundary between male and female language. The existence of gender-neutral language and cross gender usage was disregarded. This gender stereotyping is not only misleading but also has reinforced the traditional gender norms. So the author suggested the usage of research-based material when adapting textbooks. She introduced some empirical-based resources for the teachers to teach complaints, requests and conversation closings. It serves to illustrate how the pragmatic instruction should be conducted in class. Ishihara's article is an overview of the literature on pragmatic textbooks research in recent years. It's worth noting that it included the conception of "conversation implicature" and "gender language" into the analysis of the instruction material. These can serve as extra criteria for the second language teachers when they select or adapt teaching resources in the future.

In an another article written by Cohen and Ishihara (2010), it mentioned the use of authentic language data, conversation analysis and electronic data in the pragmatic instruction. Two studies were mentioned in the paper to illustrate the application of CA. One study is the comparison of telephone openings by L1 speakers of Farsi and L1 speakers of German using CA. It found that Iranian and German telephone openings are different in that Iranian included inquiries about people's health and family in their openings while German openings tend to be short and lack ritual inquiries. The second study dealing with the responses to compliments has shown the advantages of CA when comparing German and American responses to compliments. It found, in the explanation of the transcribed conversation, 
that Germans usually respond to the compliment by giving a same strength second assessment ( e.g. I know, right?) , which is rare in American conversations where people usually downgrade when they give second assessment.

In the article, the author also introduced two types of instruction activities where CA can be included in the pragmatic teaching. The first one used the example of the question "Did you have a good weekend" in French. The following teaching procedures were suggested to make the students aware of the different responses in Australia and France. (1) discussion of stereotypes of L1 and L2 cultures and how they originate from differences in cultural norms; (2) comparison of L1 and L2 responses to the question "Did you have a good weekend?"; (3) discussion of different features of conversation in French and Australian English; (4) reconstruction of the conversation in L2; (5) role plays;(6) peer assessment of each other's role play. The second example focuses on the negotiation of refusals in Spanish. The following steps were proposed: (1) identification of speech act; (2) introduction of the conception of politeness and indirectness in refusals; (3) listening to the L1 and L2 refusals and discussion about the differences in the conversations; (4) use of naturalistic data to examine refusal strategies and discussion of the refusal strategies; (5) analysis of the organization of natural discourse; (6) role play and peer feedback.

The use of language corpora in pragmatic instruction is also proposed in this study. A language corpus is defined as "a large collection of computerized texts available using corpus software programs".(Biber et al, 1998,p4). One way to use electronic corpus in pragmatic teaching is to take a phrase used in a specific speech act and search the database for contextualized examples. Searching for words or language structures that have been tagged would be preferred. However, the author noticed the lack of correspondence between language form and pragmatic meaning which makes the application of linguistic corpora limited. Since locating forms that performs a specific function in a corpus can be difficult, corpus studies of L2 pragmatics usually focuses on formulaic expressions or prefabricated chunks. She advised that if the desired material was not available in the corpus, teachers could manually annotate the functional categories. In addition, teacher should edit data from a corpus before using them for instruction since the raw data have many false starts, discourse markers and ellipsis that are distracting. It is also suggested that when material from a corpus was used, the curriculum writers should add certain details by way of a footnote.

Although the application of $\mathrm{CA}$ and electronic corpus to pragmatic research is still far from enough and its effectiveness in the instruction is debatable, this paper offers some insightful advices on how the teachers should explore ways to utilize authentic language and instruction materials in their pragmatic teaching.

\section{TeSts AND Assessment of PRAgmatic AbiLity}

Brown (2001) in his research listed six types of instruments to test second language learners' pragmatic ability. They are written discourse completion tasks(WDCT), multiple choice discourse completion tasks(MDCT), oral discourse completion tasks(ODCT), discourse role-play tasks(DRPT), discourse self-assessment tasks (DSAT) and role play self-assessments(RPSA). The research compared the six types of measures both in EFL (English as foreign language) class and JSL (Japanese as a second language) class. The participants in the EFL study are 25 volunteers from an English language program and they spent 3 hours to finish all six types of tasks. The participants in the JSL study are 47 American learners of Japanese at universities in Tokyo. The questions used on the six measures are to test students' use of the speech acts: requests, refusals and apologies. Eight items were created for every speech acts. So there are twenty four items for all the six tests except the DRPT and RPSA. DRPT was designed in 8 scenes and RPSA contain only eight items. The responses in WDCT, ODCT, DRPT and DSAT were scored by three raters on a 5-point Likert scale and RPSA were rated by learners themselves. The responses in MDCT were scored right or wrong and the number of the right answers was multiplied times 5 to maintain the same scale with other instruments. Each of the six types of test was examined for their reliability and practical features. The result of the analysis showed that the six English language versions of the tests did not work as well as the Japanese language version in terms of their reliability, variance and intercorrelations. Furthermore, EFL tests were probably subject to stronger method effects than the JSL tests. The research also demonstrated the practical features of the six types of tests. It explained that WDCT were easy to administer because they were in written format which allowed for large scale group testing. However, one of the disadvantages of WDCT was that learners could only produce and comprehend written language. The oral production was not encouraged. Plus, they were difficult to score. MDCT were both easy to administer and easy to score. However, it required only receptive language skill and couldn't test learner's oral production. The advantages of ODCT were the testing of oral production and quick to administer. However, it had disadvantages in that it required elaborate lab equipment. They were also difficult to score because they required recruiting and training of the raters. DRPT encouraged oral production but they must be done individually. DSAT encouraged self-reflection and easy to administer. However, they were not useful for high-stakes decisions. The advantages of RPSAs were the encouragement of self-reflection on pragmatics ability and easy to score. However, they were difficult to administer because they must be administered individually.

This comparative study provides statistical and practical aspects of the six tests for the test developers and test users. They can draw inferences from the research result to make their own choice in the future.

Ishihara (2010) wrote a paper focusing on the teacher based assessment of learners 'pragmatic ability in the second-language classroom. It has provided some assessment instruments, the learners' language use as well as the example teaching feedback. He suggested that the teaching of pragmatics should use research based teaching materials, 
in this way the assessment of pragmatics can show the authentic language use than the teacher's intuition and both teachers and students can refer to the data showing how native speakers respond in the similar situation. Some examples of exercise (research based information about apologizing in Japanese) are provided to show what an assessment instrument like. One type of teacher assessment is the evaluative rubric assessing learners' receptive and productive pragmatic ability. The rubric includes three areas of focus: linguistic aspects (pragmalinguisitc ability); cultural aspects (sociopragmatic ability); analytic aspects (metapragmatic ability). Some lists of specific questions and related examples are also provided for the classroom teachers to reflect upon when applying these rubrics to the assessments. The teachers can select the ones suiting their instructional purpose. When teachers assess students' pragmalinguisitc ability, they should consider their use of vocabulary/phrase; grammatical structure; strategies for a speech act; choice of pragmatic tone; use of organization; use of discourse markers and use of epistemic stance markers. When mentioning the assessment of sociopragmatic abilities, the author suggests that teachers should not only include the productive skills but also the receptive skills. When it comes to the receptive skills, it means students should learn to interpret what others say. The assess instruments of receptive skills can be elicitation of the explanation of speakers' intended meaning and acceptability judgments using multi-choice questions or questionnaires, both of which are provided with detailed examples. As to the assessment of learner's productive skills, some examples of analytic scoring instruments, learners' language and teacher feedback are given. The third one is the assessment of students' metapragmatic ability. Again two examples are given that elicit the students' analysis of how L1 and L2 are used in authentic context.

With the discussion of the value of research-based material in assessing pragmatics and its examples, the author reminded that teachers should distinguish more important pragmatic features from the less important one, focusing on the ones likely to cause serious pragmatic failure. Another factor which should be taken into consideration is that some learners might want to behave differently from what is expected in the target culture norm in order to preserve their subjectivity and identity. In such cases, the teachers should respect their intentions. The authors provides some suggestions and examples of assessment based on learners' intentions.

Besides teacher assessment, students' self-assessment can afford learners with an opportunity for evaluate themselves. This can take the form of metapragmatic reflection which entails students' evaluation of their own L2 awareness and production. In this process, the teachers are advised to provide scaffolding which can direct students' attention to key features of pragmatics. Learners' self-assessment can be put side-by-side with the teachers' assessment so that they can compare them.

This research has provided the classroom teachers with evaluation rubrics to follow when they assess students' pragmatic ability. Also, a huge number of detailed examples and suggestions are given as to the teacher assessments and students' self-assessments. The various types of framework for practice can enhance future pragmatic teaching.

\section{CONCLUSION}

In this paper, a body of select literature is reviewed as to instructional methods, teaching materials, and test and assessment in the classroom. Pragmatics involves various types of elements - language forms and functions, situational contexts, social relationships between the speakers, cultural norms. A huge variety of possibilities and challenges involved in teaching pragmatics has made it an extremely challenging task. Likewise, in the era of poststructuralism, there are additional issues to consider when it comes to the pragmatic instruction, such as pragmatic norms for teaching, learners' subjectivity and identity when following these community norms. Although these different types of issues have created many questions for both the researchers and teachers, answers will be given continually as to the best instructional choices for the learners' pragmatic development. The many challenges and opportunities we are currently facing will continue to expand future study in the area of interlanguage pragmatics and applied linguistics.

\section{ACKNOWLEDGEMENTS}

I would like to express my heartfelt gratitude to $\mathrm{Li} \mathrm{Li}$, who has offered me valuable suggestions in the academic studies. In preparation of this paper, she has spent much time reading through each draft and provides me with inspiring advice. Without her insightful criticism, the completion of this thesis wouldn't have been possible. This paper is supported by a grant from Tianjin Philosophical and Social Sciences Planning Research Project in 2018---A Study Into the Use of Classroom Pragmatics Strategies by Preschool Teachers on Their Pupils (project number:TJWW18-012).

\section{REFERENCES}

[1] Alcón,E.\&Mart1'nez-Flor. (2008). Pragmatics in Foreign Language Context in Alco'n, E.\&Mart1'nez-Flor (ed.) Investigating Pragmatics in Foreign Language Learning, Teaching and Testing . Bristol, UK: Multilingual Matters: 3-4.

[2] Anderson, J. R. (1993). Rules of the mind. Hillsdale, NJ: Erlbaum.

[3] Biber,D., Conrad,S. \& Reppen,R. (1998). Corpus linguistics investigating language structure and use. Cambridge: Cambridge University Press.

[4] Brown, J. (2001). Pragmatic tests: Different purposes, different test. In K.R. Rose and G. Kasper (ed.) Pragmatics in Language Teaching. Cambridge: Cambridge University Press: 301-325.

[5] Crozet,C. (1996). Teaching verbal interaction and culture in the language classroom. Australian Review of Applied Linguistics. No.19.37-58. 
[6] Crystal,D. (1997). The Cambridge encyclopedia of language. New York: Cambridge University Press.

[7] DeKeyser, R. (2007). Practice in a second language: Perspectives from applied linguistics and cognitive psychology. Cambridge: Cambridge University Press.

[8] House, J. (2008). Using Translation to improve pragmatic competence in Alco'n, E.\&Mart1'nez-Flor (ed.) Investigating Pragmatics in Foreign Language Learning, Teaching and Testing. Bristol, UK: Multilingual Matters: 135-152.

[9] Ishihara, N. (2010). Adapting textbooks for teaching pragmatics in Ishihara, N. \& Cohen, A. (ed.) Teaching and learning pragmatics: Where language and culture meet. Harlow, UK: Pearson Longman:145-165.

[10] Ishihara, N.\& Cohen, A. (2010). Discourse, interaction, and language corpora in Ishihara, N.\& Cohen, A. (ed.) Teaching and learning pragmatics: Where language and culture meet. Harlow, UK: Pearson Longman:177-243

[11] Ishihara,N. (2010). Assessment of pragmatics in the classroom. In Ishihara, N., \& Cohen, A. (ed.) Teaching and learning pragmatics: Where language and culture meet. Harlow, UK: Pearson Longman: 286-311.

[12] Kondo,S. (2008). Effects on pragmatic development through awareness-raising instruction: refusals by Japanese EFL Learners in Alco'n, E. and Martı'nez-Flor, (ed.) Investigating Pragmatics in Foreign Language Learning, Teaching and Testing. Bristol, UK: Multilingual Matters: 153-179.

[13] Leech,G. (1983). The principles of pragmatics. London: Longman.

[14] Lddicoat, A.J. \& Crozedt, C. (2001). Acquiring French interactional norms through instruction. In K.R. Rose and G. Kasper (ed.) Pragmatics in language teaching. Cambridge: Cambridge University Press: 125-144.

[15] Li, S. (2012). The effect of input-based practice on pragmatic development in L2 Chinese. Language Learning. $403-438$.

[16] Takimoto, M. (2009). The effects of input-based tasks on the development of learners' pragmatic proficiency. Applied Linguistics.No.30. 1-25.

[17] Thomas, J. (1983). Cross-cultural pragmatic failure. Applied Linguistics. No.4. 91-112.

[18] VanPatten, B. (2007). Input processing in adult second language acquisition. In B. VanPatten \& J. Williams (ed.) Theories in second language acquisition: An introduction. Mahwah, NJ: Erlbaum: 115-135.

[19] VanPatten, B. \& Oikkenon, S. (1996). Explanation versus structured input in processing instruction. Studies in Second Language Acquisition. No.18. 495-510.

Liwei Zhu was born in Jilin, China in 1981. She received her M.D. in Foreign Linguistics and Applied Linguistics in Beihua University, China in 2006. Her research interests include applied linguistics, TESOL and English literature. 